\title{
A PROCESS ANALYTICAL TECHNOLOGY (PAT) APPROACH TO EVALUATE GABAPENTIN DISTRIBUTION IN LAMINAR EXTRUDATES
}

\author{
JOANNA RONOWICZ ${ }^{1 *}$, JOÃO F. PINTO ${ }^{2}$ \\ ${ }^{I}$ Department of Inorganic and Analytical Chemistry, Faculty of Pharmacy, Collegium Medicum in Bydgoszcz, Nicolaus \\ Copernicus University in Toruń, ul. Jurasza 2, 85-089 Bydgoszcz, Poland \\ ${ }^{2}$ Department of Galenic Pharmacy and Pharmaceutical Technology, Faculty of Pharmacy, University of Lisbon, Av. Prof. \\ Gama Pinto, 1649-003 Lisbon, Portugal
}

*corresponding author: joanna.ronowicz@cm.umk.pl

Manuscript received: September 2020

\begin{abstract}
The work combines the use of fast and non-destructive analytical techniques for rapid on-line process monitoring and evaluation of the drug product quality, within the Process Analytical Technology strategy recommended by regulatory authorities, applied to laminar extrudates designed to deliver gabapentin orally. Laminar extrusion is a promising technology to deliver drugs in different polymorphic forms by different release kinetics. The work focuses on accessing the homogeneity of gabapentin's (GABA) distribution in laminar extrudates by Raman and Attenuated Total Reflectance Fourier Transform Infrared (ATRFTIR) spectroscopies as PAT tools. In the framework of the project, the evaluation of formulation and process factors impacting on gabapentin polymorphic form was also carried out by differential scanning calorimetry (DSC) and X-ray powder diffraction (XRPD). It has been observed that the addition of water during manufacturing process of extrudates was a critical formulation factor that might had promoted the conversion of crystalline gabapentin into its amorphous form. Raman imaging indicated that gabapentin was distributed homogeneously in the investigated laminar extrudates without the detection of agglomerates in the Raman map. The results of XRPD, DSC and ATR-FTIR analysis confirmed that gabapentin was present as the amorphous form of the drug in the laminar extrudates.
\end{abstract}

\section{Rezumat}

Studiul de față combină utilizarea unor tehnici analitice rapide și nedistructive privind monitorizarea rapidă online a proceselor și evaluarea calității produselor medicamentoase, în cadrul strategiei de tehnologie analitică a proceselor (PAT), recomandată de autoritățile de reglementare, aplicată extrudatelor laminare concepute pentru a administra gabapentina pe cale orală. Extrudarea laminară este o tehnologie promițătoare pentru a genera medicamente în diferite forme polimorfe, folosind diferite cinetici de eliberare. Lucrarea se concentrează pe obținerea omogenității distribuției gabapentinei (GABA) în extrudate laminare, prin spectrometria Raman și spectrometria FTIR cu reflexie totală atenuată (ATR-FTIR), ca instrumente PAT. A fost realizată evaluarea factorilor legați de formulare și de proces, cu impact asupra formei polimorfe de gabapentină, prin calorimetrie de scanare diferențială (DSC) și difracție cu raze X (XRPD). S-a observat că adăugarea de apă în timpul procesului de fabricație al extrudatelor a reprezentat un factor critic de formulare, care ar fi putut determina conversia gabapentinei cristaline în forma sa amorfă. Imagistica Raman a indicat faptul că gabapentina a fost distribuită omogen în extrudatele laminare investigate, fără detectarea aglomeratelor pe harta Raman. Rezultatele XRPD, DSC și ATR-FTIR au confirmat că gabapentina a fost prezentă sub formă amorfă în extrudatele laminare.

Keywords: ATR-FTIR spectroscopy, gabapentin, laminar extrusion, Process Analytical Technology

\section{Introduction}

Current trends in pharmaceutical industry are focused on the application of fast and non-destructive techniques for on-line process monitoring and evaluation the drug product quality. By using advanced non-invasive analytical techniques, it is possible to closely monitor the pharmaceutical manufacturing process $[3,4,15,24$, 26]. This approach is in accordance with the Process and Analytical Technology (PAT) strategy which is currently recommended by regulatory authorities such as the European Medicines Agency and US Food and Drug Administration [9, 10, 12]. The non-invasive techniques allow to improve and simplify the process control strategy making possible the real-time release of medicines by the pharmaceutical industry $[5,7$, 11, 14]. Furthermore, by providing permanent quality control, the techniques used online can detect prematurely problems that might occur during the process of manufacturing, namely degradation of the drug substance, polymorphic form changes or heterogeneity on drug substance distribution within the dosage form fulfil the current challenges that the pharmaceutical industry is facing $[4,15]$. 
Many active pharmaceutical ingredients (API) present polymorphism, with the unstable forms converting into the one that is the most thermodynamically stable $[13,23,27]$. Consequently, it is crucial to monitor the polymorphic form of the API and confirm the stability or the conversion of that form throughout the process of manufacturing of the drug product. Particularly critical is the potential effect of temperature, moisture or pressure, often required for the transformation of a mixture of solid materials into a dosage form, on an unstable polymorphic form of the drug substance [2, 19, 25]. Most of the active pharmaceutical ingredients, especially newly synthesized molecular entities present low water solubility and consequently their bioavailability and therapeutic efficacy are inappropriate. In presence of this, there is a great need of searching for practical solutions for improved therapeutic responses by bioactive molecules.

Laminar extrusion can be considered as a promising technology to accommodate drug substances in a polymorphic form presenting high water solubility than the most stable polymorph, provided that the polymorph remains stable throughout the process of manufacture. Several studies investigating the technology of laminar extrusion have been carried out [16-18]. In laminar extrudates, the number and thickness of layers are crucial. A thicker layer may result in a slower drug release and therefore a prolonged therapeutic effect. By selection of the appropriate type and fraction of polymers as well as number and thickness of layers, the release of active pharmaceutical ingredients can be tailored to maximize the therapeutic effect. By using the so-called co-extrusion and incorporation of two active substances in two different layers, it is possible to obtain an oral dosage form containing two incompatible active pharmaceutical ingredients with completely different physicochemical properties. Laminar extrusion is a good example of continuous manufacturing which is currently a hot topic in the pharmaceutical industry. Continuous manufacturing offers numerous advantages, such as speeding drug development stage, reduction the manufacturing time and even avoidance scale up problems because the same equipment is used during the lab and production scale [14, 20-22]. Although laminar extrusion technology seems to be very promising, it is still not a standard in pharmaceutical technology. Further studies on this topic are therefore recommended in order to better describe and understand this manufacturing process and the influence of process parameters on the drug product quality. Therefore, the use of analytical methods that allow real time and continuous measurements to evaluate raw materials, intermediates, bulk products and drug products without the need for sampling, prevent interruption of the production line and delays in the manufacturing time, maximizing the efficiency of the manufacturing process and minimizing costs of manufacture.
Laminar extrusion is a suitable technique to produce novel dosage forms for a tailored oral delivery of drug substances. Extrudates can be cut into different sizes allowing for a convenient adjustment of the drug dose for specific dose needs (e.g. paediatrics or geriatrics) which are difficult to meet with conventional dosage forms such as tablets. Due to the possibility of cutting the manufactured laminar extrudates in order to adjust the drug dose to specific patient's needs, the homogeneity of drug substance's distribution in laminar extrudates seems to be crucial to assure a desired drug product quality and accurate reproducible dosing.

This study aims to assess the distribution of gabapentin (GABA) in laminar extrudates confirming their homogeneity. For that purpose, the work considers the application of non-destructive spectroscopic techniques to determine the distribution of gabapentin in the extrudates. The usefulness and the possibility of the application of spectroscopic techniques, such as the Attenuated Total Reflectance Fourier Transform Infrared (ATR-FTIR) spectroscopy or Raman imaging as PAT tools for non-destructive evaluation of gabapentin content in multilayer laminar extrudates was assessed. In the framework of the project, the evaluation of formulation and process factors impact on gabapentin polymorphic form was also carried out.

\section{Materials and Methods}

\section{Materials}

The multilayer laminar extrudates were prepared from cellulose microcrystalline (MCC, Avicel PH 101, FMC Corp. USA), lactose monohydrate (Granulac 200, Meggle, Germany) and demineralized water $(60 \%$ w/w). Gabapentin (Supplied by Lusifar, Portugal) was used as a model drug substance in all formulations (Table I).

Table I

Composition of the formulations (\%)

\begin{tabular}{lc}
\hline \multicolumn{1}{c}{ Ingredient } & $\begin{array}{c}\text { Content } \\
(\mathbf{\%})\end{array}$ \\
\hline Gabapentin & 10 \\
Cellulose microcrystalline (Avicel PH 101) & 45 \\
Lactose monohydrate (Granulac 200) & 45 \\
Water * & 60 \\
\hline
\end{tabular}

* Water was removed from extrudates by drying until constant moisture content $(<5 \%)$

\section{Preparation of laminar extrudates}

Powders were dry blended in a planetary (Kenewood Chef, UK) mixer for $10 \mathrm{~min}$, demineralized water was slowly added and mixing continued for another $10 \mathrm{~min}$. The obtained wet masses were left at room temperature for $24 \mathrm{~h}$ prior to extrusion in a ram extruder (Figure 1) at different extrusion rates (10 or $20 \mathrm{~mm} / \mathrm{min}$ ). Each wet mass was placed in a chamber allowing the manufacture of the respective layer in the extrudate obtained. 
FARMACIA, 2021, Vol. 69, 1

Different number (2 or 3 ) and types of layers (a placebo layer and a layer with API embedded) were considered. Extrudates were dried in an air oven (Heraus, Germany) at the temperature of $50^{\circ} \mathrm{C}$ for
12 hours, and then stored at room temperature prior to characterization. Formulation and process parameters are provided in Table II.

Table II

Formulation and process parameters

\begin{tabular}{lccc}
\hline & \multicolumn{3}{c}{ Formulation } \\
\cline { 2 - 4 } & LE 1 & LE 2 & LE 3 \\
\hline Extrusuion rate (mm/min) & 10 & 20 & 20 \\
\hline Extension (mm) & 150 & 150 & 150 \\
\hline Number and type of layers & $\begin{array}{c}\text { 2 layers } \\
\text { of API }\end{array}$ & $\begin{array}{c}\text { 2 layers } \\
\text { of API }\end{array}$ & $\begin{array}{c}\text { 2 outer layers of placebo } \\
\text { 1 middle layer of API }\end{array}$ \\
\hline
\end{tabular}

\section{ATR-FTIR spectral measurements}

FTIR measurements were carried out using a FTIR spectrometer (FTIR 8400S, Shimadzu, Japan) equipped with ATR accessory (PIKE MIRacle). The samples were placed onto the surface of the ATR crystal $(\mathrm{Ge})$ and FTIR spectra were recorded from $600 \mathrm{~cm}^{-1}$ to $4000 \mathrm{~cm}^{-1}$ at a resolution of $2 \mathrm{~cm}^{-1}$. Each spectrum was an average of 30 scans to increase the signal to noise ratio. For each scanning, the spectrum was collected by subtracting the original spectrum from the air background spectrum.

In order to evaluate the homogeneity of the API distribution in laminar extrudates, the spectra were recorded in 10 different surface locations of the extrudates' samples (on both surfaces of extrudates). Raman imaging was used as a reference method.

Diffractometric (XRPD) characterization of gabapentin in extrudates

X-ray powder diffraction (XRPD) measurements were also carried out to assess GABA polymorphic form in laminar extrudates. A powder X-ray diffractometer (MiniFlex Rigaku) was used to assess the crystallinity of gabapentin in the drug loaded extrudates. Samples were scanned from 2 Theta: $2^{\circ}$ to $40^{\circ}$ at a rate of $1 \%$ min

Thermal (DSC) characterization of gabapentin in extrudates

A differential scanning calorimetry (DSC Mettler Toledo, Switzerland) was used to perform a thermal analysis. Samples were placed in a $40 \mu \mathrm{L}$ standard aluminium pan. The analysis was carried on under a nitrogen environment ( $30 \mathrm{~mL} / \mathrm{min})$. The samples were heated from $30^{\circ} \mathrm{C}$ to $250^{\circ} \mathrm{C}$ at a rate of $10^{\circ} \mathrm{C} / \mathrm{min}$.

Raman imaging

Confocal Raman imaging was used as a reference method in order to evaluate the homogeneity of GABA distribution in laminar extrudates. Measurements were carried out with a Raman spectrometer (WITec alpha 300) which was connected with a confocal microscope, equipped with TrueSurface attachment and EMCCD detector for ultra-fast and sensitive imaging. The samples were irradiated with a focused laser beam. The laser was emitting at the wavelength of $785 \mathrm{~nm}$.
Design of simulation studies of the impact of the formulation and process factors on gabapentin polymorphic form

Simulation studies were carried out to verify which process or formulation factor was critical on the conversion of crystalline gabapentin into its amorphous counterpart form. The impact of compression, wetting and drying on the drug substance was assessed. In order to evaluate the impact of compression, the pure gabapentin was subjected to pressure in a hydraulic press to obtain a disk. The simulation studies were supported by ATR-FTIR spectroscopy and XRPD diffractometry.

\section{Results and Discussion}

The use of simple and commonly used excipients, such as lactose monohydrate, microcrystalline cellulose and water, embedding gabapentin present in $10 \%$ has made possible the manufacture of extrudates without defects, as observed by visual inspection of mono, bi and triple layers extrudates. The force of extrusion at steady state remained constant indicating the adequate plasticity of the wet masses to allow a constant flow of the masses through the die. The rectangular section of the extrudates enabled sampling of them, in which samples of different sizes (i.e., weights) could be obtained and dried until a constant moisture content below $5 \%$.

ATR-FTIR spectra

The ATR-FTIR spectra were registered for raw materials (controls) and laminar extrudates without major concerns or difficulties. The use of the ATR-FTIR technique was considered due to its non-invasive nature, no need for special sample preparation, short time needed to register the infrared spectrum and a small amount of sample needed to perform the test. Figures 1 and 2 present the spectra for the gabapentin, lactose, and microcrystalline cellulose and the laminar extrudates (LE 1-3).

The gabapentin spectrum exhibits sharp IR spectral peaks which can be used as a fingerprint for GABA in the extrudates (Figure 1). The spectrum exhibits an absorption band in the region of $3100-2800 \mathrm{~cm}^{-1}$ due to the $-\mathrm{NH}_{3}{ }^{+}$stretching vibration. The IR bands 
at the wavenumbers of $1567 \mathrm{~cm}^{-1}$ and $1547 \mathrm{~cm}^{-1}$ could be assigned to $\mathrm{NH}_{3}{ }^{+}$deformation vibration in the 1500 to $1350 \mathrm{~cm}^{-1}$ wavenumbers interval the bands observed corresponded to the asymmetric carboxylate band and/or $\mathrm{CH}_{2}$ deformation band. In the spectrum of the laminar extrudates (LE 1), it was hard to identify characteristic peaks for GABA, whereas the absorption peaks characteristic for lactose could easily be observed (Figures 1 and 2). Figure 3 presents the spectra taken from 10 different locations on both sides of the extrudates, showing no differences between locations and intensities in the recorded IR spectra. The characteristic absorption bands of crystalline gabapentin were not observed in the registered spectra.
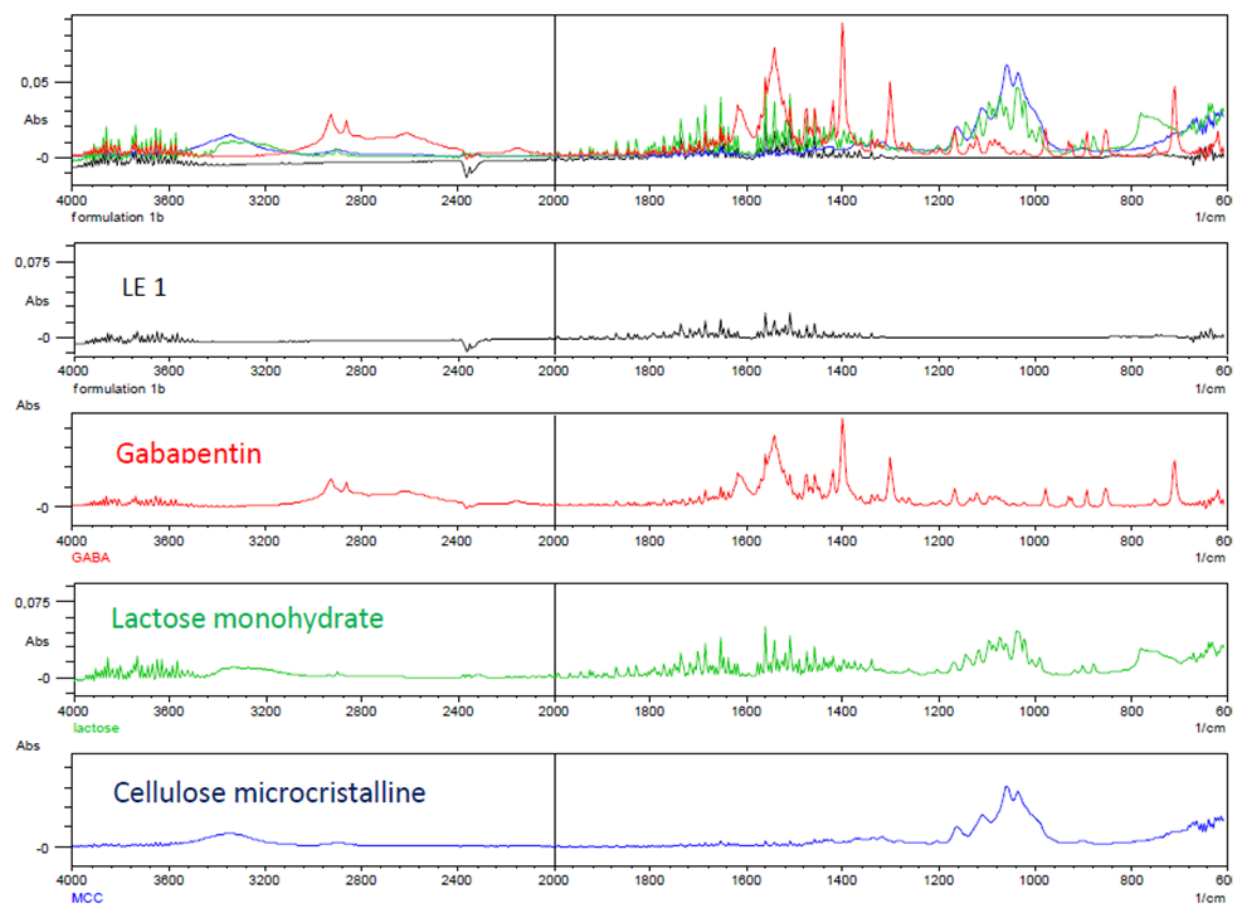

Figure 1.

The ATR-FTIR spectra recorded for raw materials (gabapentin, lactose monohydrate and microcrystalline cellulose) and for the laminar extrudate (LE 1)
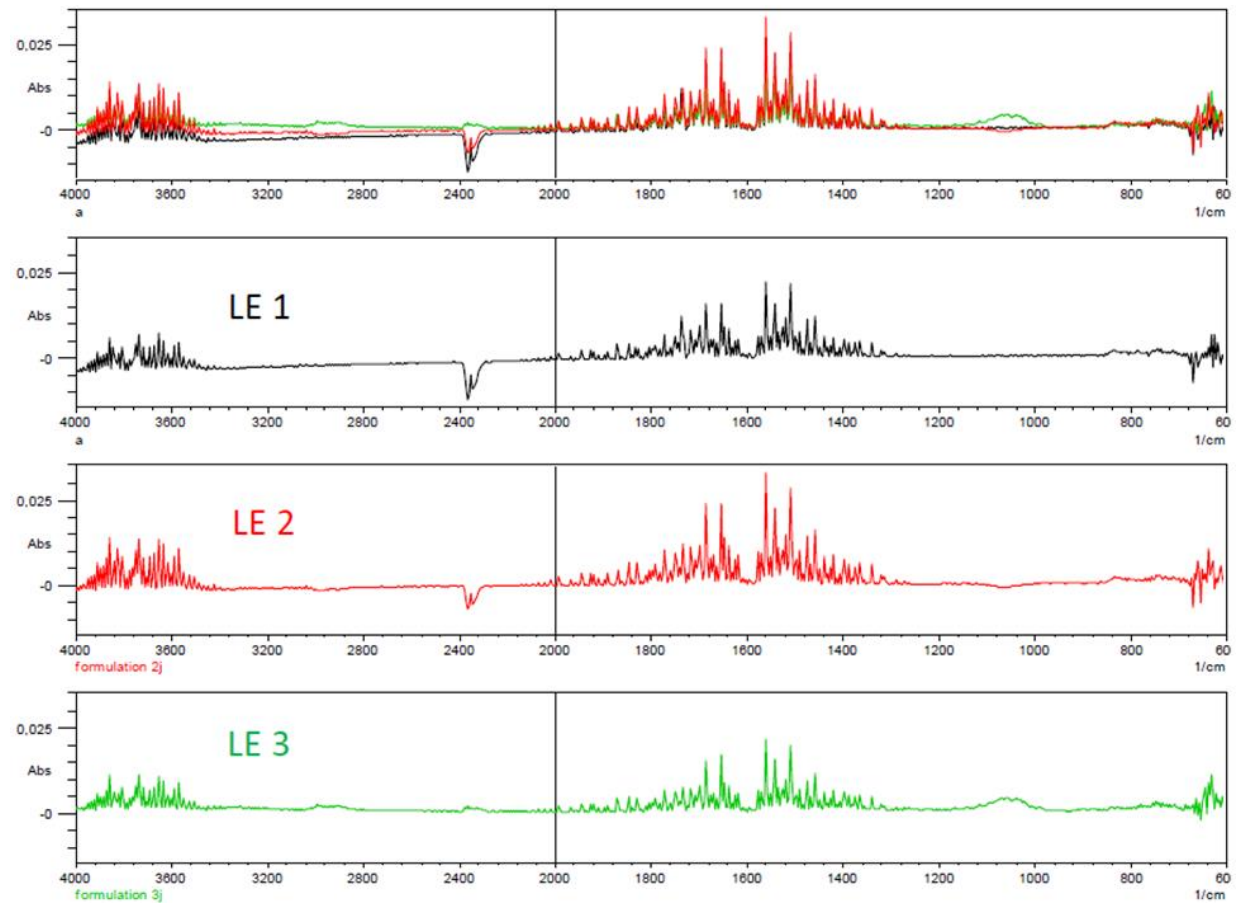

Figure 2.

The ATR-FTIR spectra recorded for the investigated laminar extrudates (LE 1-3) 

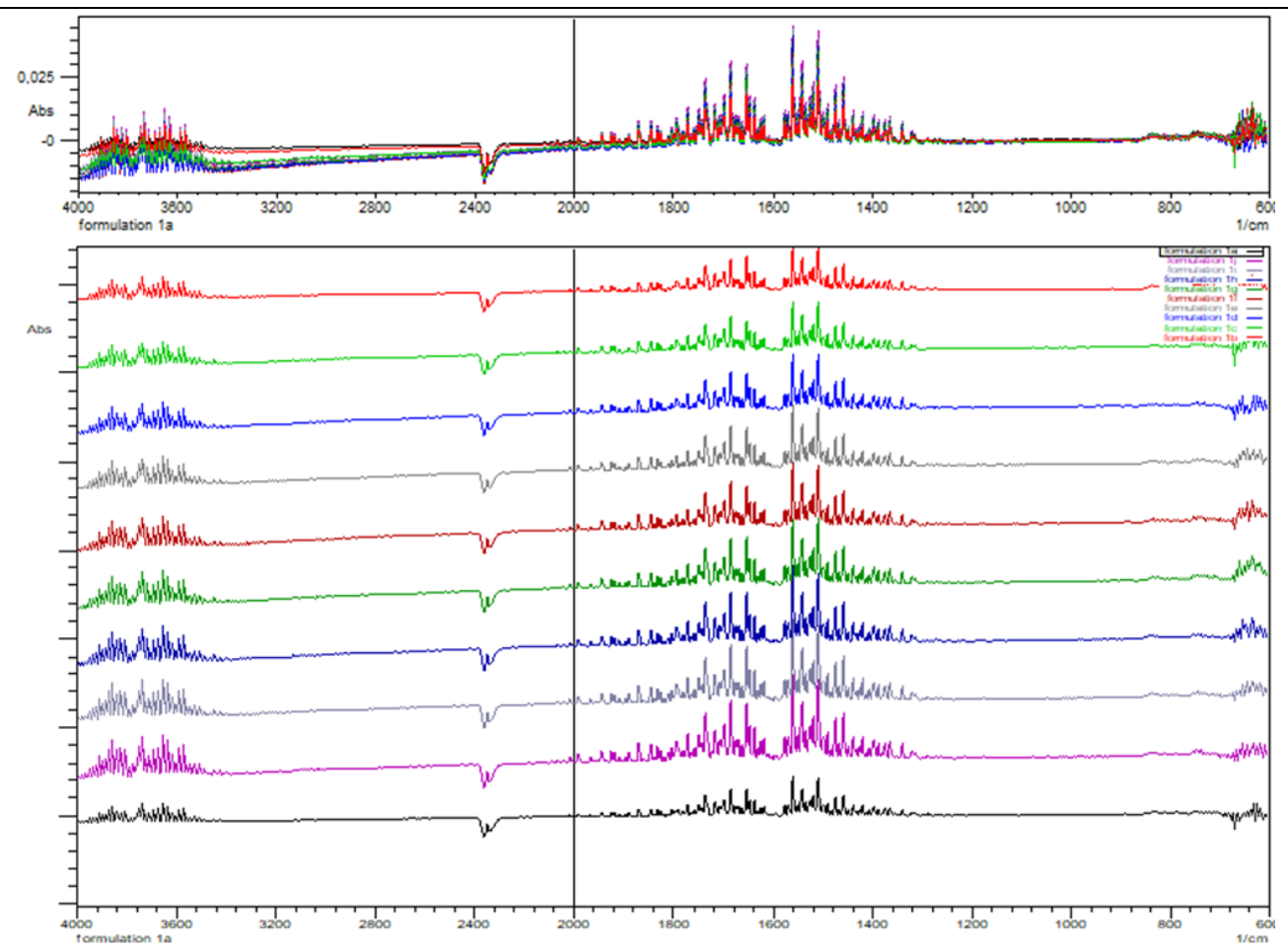

Figure 3.

The ATR-FTIR spectra of the examined laminar extrudate (LE 1) - the spectra were recorded in 10 different locations of examined sample

\section{Raman imaging results}

Confocal Raman imaging was used as a reference method in order to evaluate the homogeneity of GABA distribution in laminar extrudates. Based on Raman image (Figure 4), it can be concluded that gabapentin is distributed homogeneously in the investigated laminar extrudates without the presence of agglomerates in the Raman map.
Raman imaging provides information about a chemical composition of samples, reflecting the distribution of all components of the formulation in the final pharmaceutical dosage form. Although the technique is non-destructive and does not require any special sample preparation, mapping surfaces is time-consuming making it difficult to be applied in a continuous process monitoring, making the technique a reference method rather than a practical one.

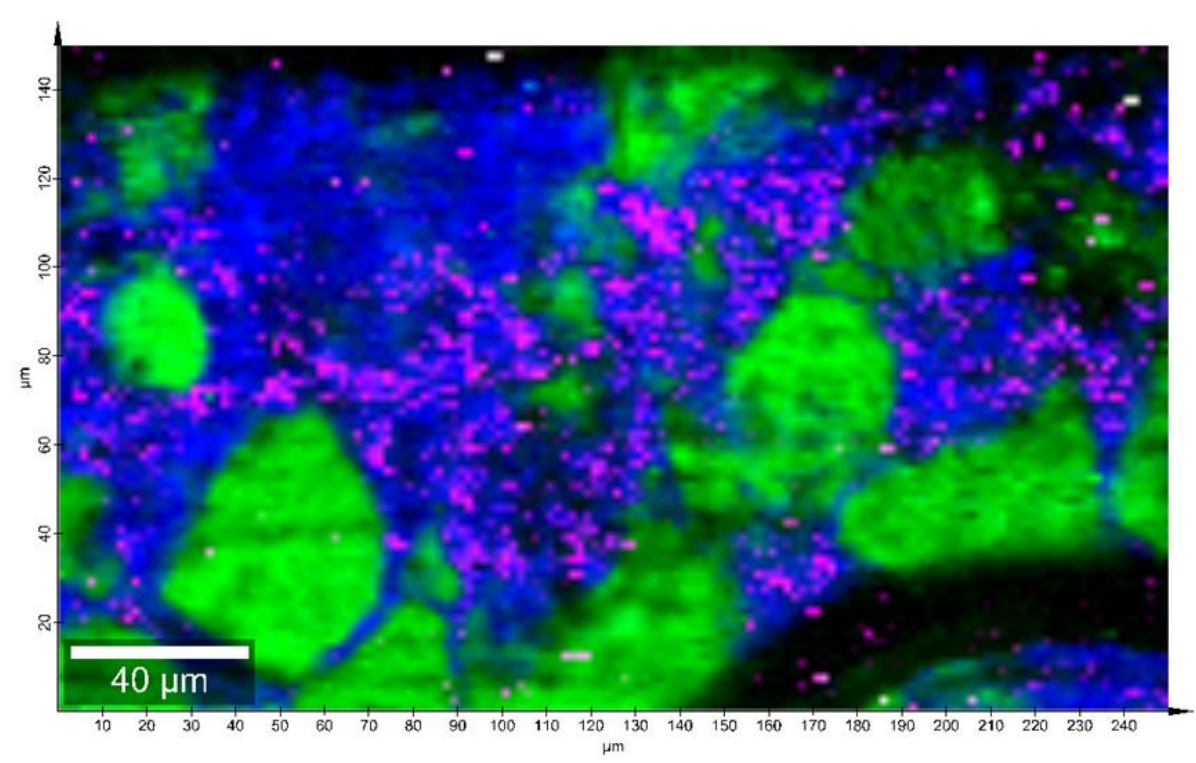

Figure 4.

Image (map) from Raman spectroscopy of the laminar extrudate (pink - gabapentin; blue - lactose monohydrate; green - microcrystalline cellulose) 


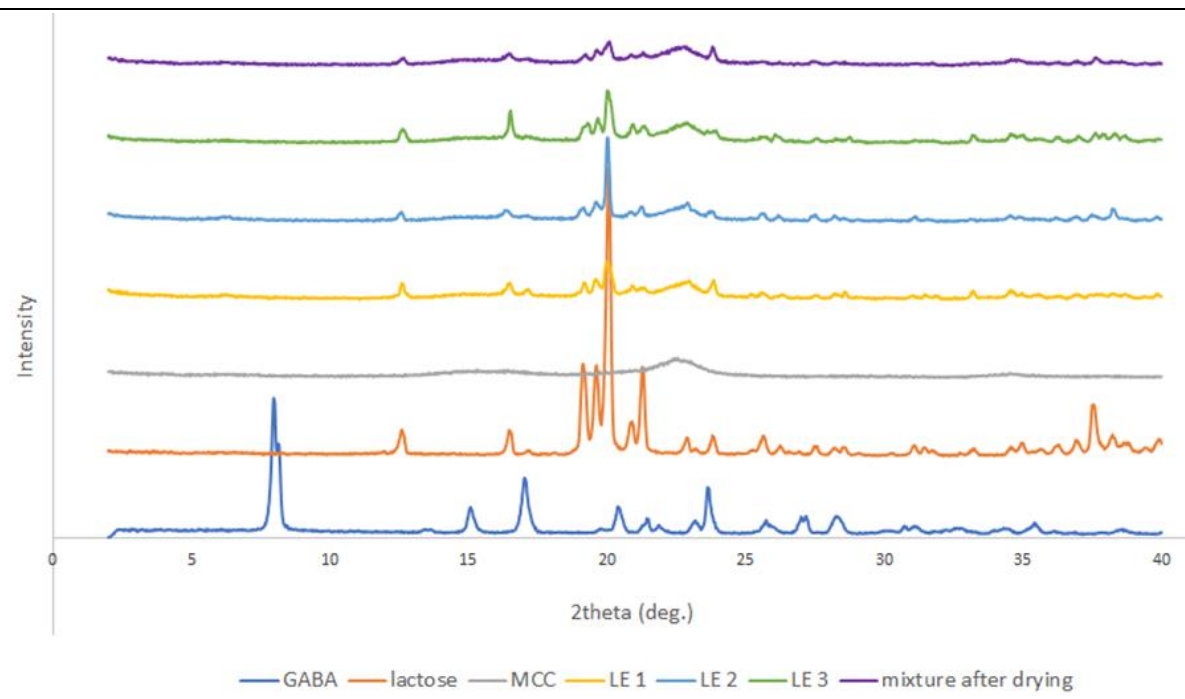

Figure 5.

Characterization of raw materials, physical mixtures and laminar extrudates by XRPD diffractometry

Results from the crystallographic (XRPD) analysis The diffractogram of crystalline gabapentin (Figure 5), with typical diffraction peaks observed at $2 \theta: 8.7^{\circ}$, $15.1^{\circ}, 17.0^{\circ}, 20.4^{\circ}$ and $23.7^{\circ}$, was different than the diffractogram of the extrudates sample in which these peaks were not observed.

The absence of such peaks in gabapentin loaded laminar extrudates suggests that the drug substance was present in its amorphous form in all investigated formulations.
Results from the calorimetric (DSC) analysis Similarly to the XRPD analysis, the absence of an endothermic peak of GABA due to the melting of crystalline gabapentin present in the drug loaded extrudates suggests that the drug substance was present as the amorphous form in the matrix made of crystalline lactose and microcrystalline cellulose (Figure 6).

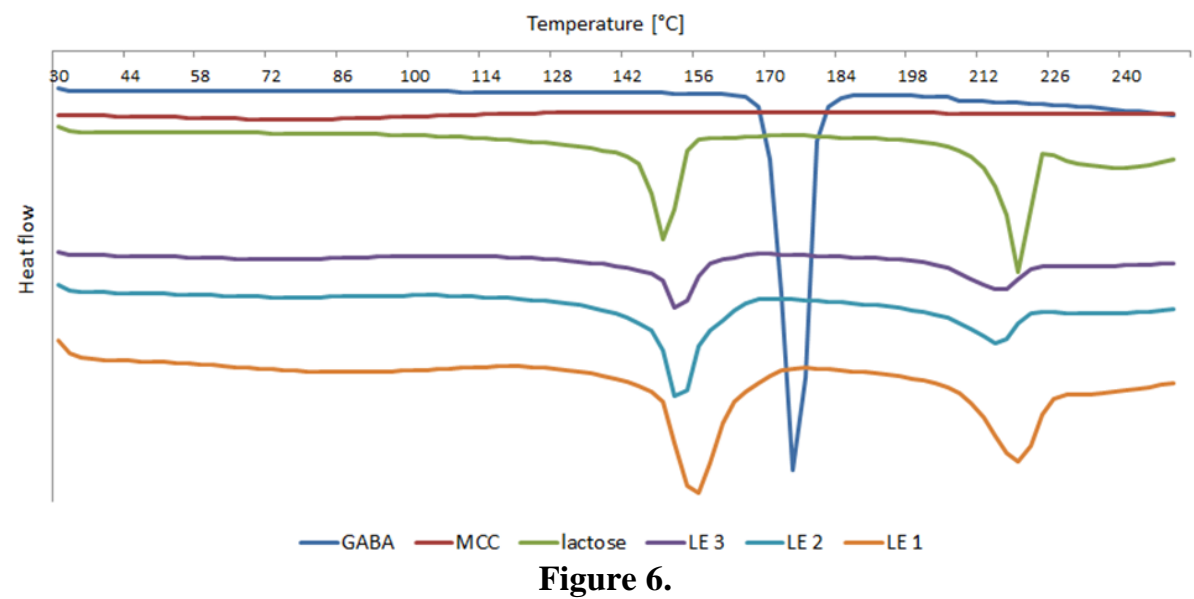

Characterization of raw materials and laminar extrudates by DSC calorimetry

Evaluation of the impact of the formulation and process factors on gabapentin polymorphic form simulation studies

The impact of compression was assessed. The XRPD diffractograms registered for a crystalline gabapentin and gabapentin after compression are depicted in Figure 7. The impact of wetting and drying on the drug substance was also assessed. The ATR-FTIR spectra of a pure gabapentin and gabapentin after wetting and drying were registered and compared. The registered ATR-FTIR spectrum for gabapentin exposed to moisture and drying displays a typical broad amorphous halo with the absence of sharp absorption peaks signals characteristic for crystalline form (Figure 8).

The ATR-FTIR spectrum of gabapentin presents intense bands at 1615, 1540, 1400, 1300 and $708 \mathrm{~cm}^{-1}$ whereas none of them were observed for gabapentin exposed to water prior to drying (Figure 8). The ATR-FTIR spectrum of gabapentin after exposure to moisture did not show any spectral sign that can be related to crystalline gabapentin. These differences 
in both spectra can be explained by a polymorphic change in GABA form. Combining the findings with the thermal analysis and crystallographic evaluation (Figures 5 and 6), it can be concluded that one of registered ATR-FTIR spectra presents gabapentin in amorphous form (Figure 8). The spectroscopic results depicted in Figure 8 indicate a significant difference in the two registered ATR-FTIR spectra, showing no similarity between the spectrum of pure GABA and the spectrum of processed gabapentin. The spectrum of processed gabapentin did not show characteristic crystalline gabapentin peaks that would suggest a significant change in the polymorphic form of the drug substance. These results support the findings observed in the spectra collected for extrudates samples (Figures 1 and 2) in which only the characteristic peaks of lactose were recorded.

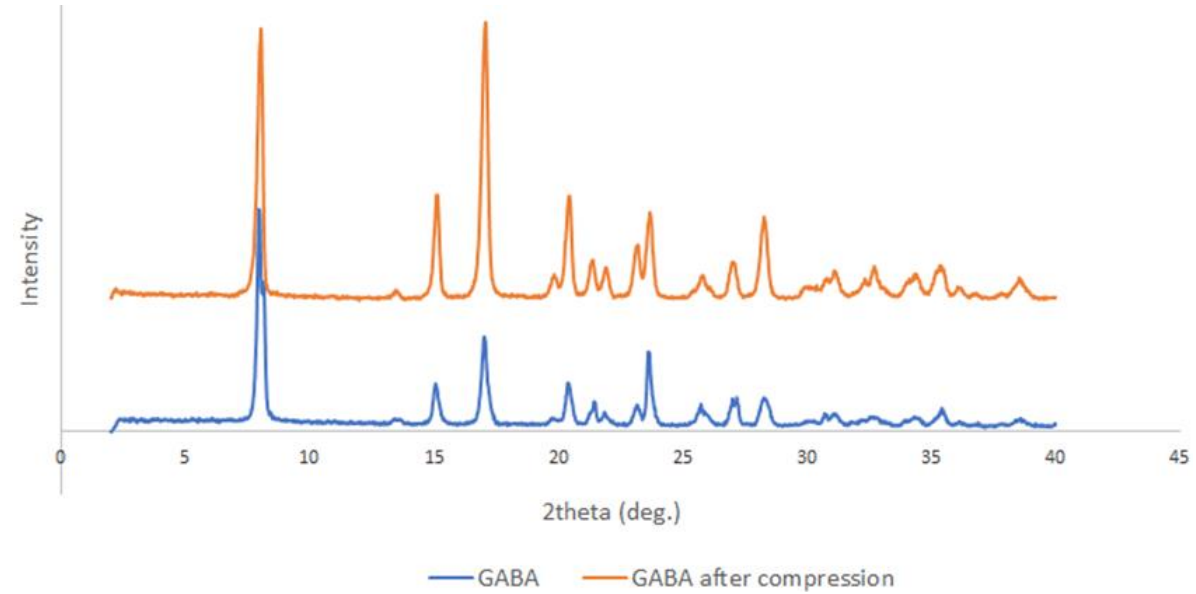

Figure 7.

Comparison of pure gabapentin and gabapentin after compression by XRPD diffractometry
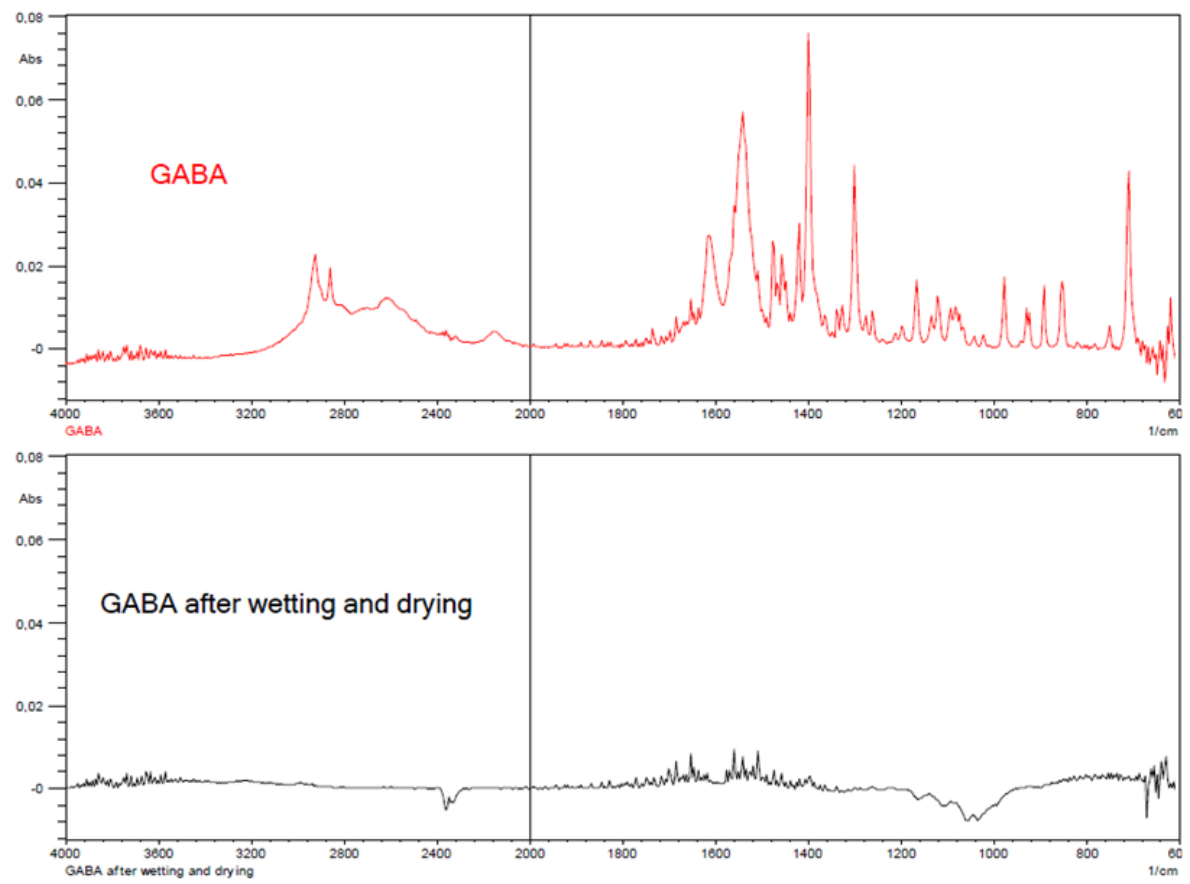

Figure 8.

Comparison of pure gabapentin and gabapentin after wetting and drying by ATR-FTIR spectroscopy

Regarding the effects of manufacturing stress on chemical stability, in these research studies laminar extrudates were manufactured in the absence of organic solvents at room temperature and by using low extrusion forces, the shear forces were also low contributing to keep intact the properties of the original drug particles. The absence of toxic organic solvents in the process makes this technology environmentally friendly (green technology) with a broad potential use.

The exposition to high temperatures can result in the decomposition of heat-sensitive active pharmaceutical ingredients. In wet mass extrusion, this problem is avoided as the masses are processed at ambient temperature. The process therefore offers a continuous 
production method without temperature stress, which makes it applicable for a variety of heat-sensitive active substances. According to the stability studies described in scientific papers $[1,6,28]$, gabapentin is resistant to chemical instability. Scientific literature review indicates no degradation of gabapentin after exposure to $65^{\circ} \mathrm{C}$ for 72 hours, no degradation of gabapentin after exposure to $105^{\circ} \mathrm{C}$ for one hour, no degradation of gabapentin after exposure to $50^{\circ} \mathrm{C} / 75 \%$ RH. Gabapentin was stable and remained intact upon exposure to sunlight in $\left(25-40^{\circ} \mathrm{C}\right)$ for 72 hours [1]. Due to the mild manufacturing process conditions, the problem of the occurrence of chemical degradation of gabapentin molecules during laminar extrusion process is avoided.

In these studies, the manufactured laminar extrudates were evaluated by differential scanning calorimetry, ATR-FTIR spectroscopy, X-ray powder diffraction and Raman imaging. The ATR-FTIR spectroscopy, calorimetric and X-ray diffractometry results have shown the polymorphic transitions and formation of amorphous state of the drug substance during manufacturing process. During the simulation studies, it has been observed that the addition of water during manufacturing process of extrudates was a critical factor that induced the conversion of crystalline gabapentin into amorphous form (Figures 5 and 8).

The registered XRPD pattern (Figure 5) for a physical mixture (after wetting and drying) indicates that gabapentin exists in the amorphous form. There were not observed any diffraction peaks typical for crystalline gabapentin. In the case of chemical decomposition of the active substance, there would be observed additional diffraction peaks at different positions characteristic for generated degradation products. In this study, no formation of gabapentin degradation products was observed.

It has been indicated that the addition of water during extrusion manufacturing process is a critical formulation factor that causes transition of crystalline gabapentin form into the amorphous form (Figures 5 and 8). The comparison of the XRPD diffractograms (Figure 5) suggests that the absence of characteristic peaks of gabapentin in the diffractograms recorded for samples of laminar extrudates as well as for samples of a physical mixture of gabapentin with the excipients (exposed to moisture and drying) confirmed the polymorphic transition caused by the manufacturing process condition. By opposition, the submission of gabapentin to pressure did not change the polymorphic form of gabapentin remaining crystalline (Figure 7), as the comparison of diffractograms collected before and after compression show, i.e., the exposition of GABA to compression does not cause its transition to amorphous form. Therefore, it can be postulated that the water required to transform a physical mixture into a wet mass appropriated for extrusion is sufficient to dissolve gabapentin that, up on drying, solidified in the amorphous form. That was not unexpected for a drug with a solubility in water of $>100 \mathrm{mg} / \mathrm{mL}$ [8].

\section{Conclusions}

The study has proved the ability to manufacture mono, di and triple layers laminar extrudates. It was also observed that gabapentin was homogeneously distributed in the extrudates without the presence of agglomerates, as shown by spectroscopic techniques.

Mostly interesting was the conversion of crystalline gabapentin into its amorphous counterpart, simply by exposing it to the water required for extrusion.

The results from diffraction, calorimetry and spectroscopy when combined, confirmed that gabapentin was present in the laminar extrudates in its amorphous form.

Although, the spectrum of gabapentin crystalline form indicates several characteristic bands, which could be used for its identification, the addition of water during the manufacturing process induced a polymorphic transition. Additional simulation studies supported by XRPD and ATR-FTIR analysis indicated which manufacturing process factor was crucial in transition of GABA crystalline form into an amorphous form.

\section{Acknowledgement}

This work was supported by the Nicolaus Copernicus University in Torun under the Excellence Initiative Debuts (grant IDUB 2020-1-NZ-Ronowicz) and PDB WF 514.

\section{Conflict of interest}

The authors declare no conflict of interest.

\section{References}

1. Abdallah AA, Elhag DL, Ibrahim AAM, Awadallah MA, Abdeen M, Elawni AE, Assessment of the stability of gabapentin under different stress conditions. World J Pharm Pharm Sci., 2016; 5(9): 2392-2408.

2. Antonio M, Calvo NL, Maggio RM, Chemometric study of the excipients' influence on polymorphicbehavior. Mefenamic acid as case of study. J Pharm Biomed Anal., 2019; 170(6): 8-15.

3. Bostijn N, Hellings M, Veen M, Vervaet C, Beer T, In-line UV spectroscopy for the quantification of lowdose active ingredients during the manufacturing of pharmaceutical semi-solid and liquid formulations. Anal Chim Acta, 2018; 1013(7): 54-62.

4. Burggraeve A, Silva A, Kerkhof T, Hellings M, Vervaet Ch, Remon JP, Heyden YV, Beer T, Development of a fluid bed granulation process control strategy based on real-time process and product measurements. Talanta, 2012; 100(10): 293-302.

5. Casian T, Reznek A, Vonica-Gligor AL, Van Renterghem J, De Beer T, Tomuţă I, Development, validation and comparison of near infrared and Raman spectroscopic methods for fast characterization of tablets with 
amlodipine and valsartan. Talanta, 2017; 167(5): 333-343.

6. Chaitanya M, Reddy K, Fatima H, Chowdary A, Begum A, Method development and stability studies of gabapentin in bulk and pharmaceutical dosage form. Int J Pharm Biol Sci., 2018; 8(3): 132-135.

7. De Beer T, Burggraeve A, Fonteyne M, Saerens L, Remon JP, Vervaet C, Near infrared and Raman spectroscopy for the in-process monitoring of pharmaceutical production processes. Int J Pharm., 2011; 417(1-2): 32-47.

8. Drugbank, 2020; www.drugbank.ca/ DB00996.

9. FDA Guidance for Industry PAT - A Framework for Innovative Pharmaceutical Development, Manufacturing and Quality Assurance, September, 2004.

10. FDA Pharmaceutical cGMPs for the $21^{\text {st }}$ Century, A Risk-Based Approach, Final Report, 2004.

11. Goodwin DJ, den Ban S, Denham M, Barylski I, Real time release testing of tablet content and content uniformity. Int J Pharm., 2018; 537(1-2): 183-192.

12. International Conference on Harmonization of Technical Requirements for Registration of Pharmaceuticals for Human Use, Topic ICH Q8 (R2): Pharmaceutical Development, Geneva, 2009.

13. Jacon Freitas JT, Santos Viana OMM, Bonfilio R, Doriguetto AC, Araújo MB, Analysis of polymorphic contamination in meloxicam raw materials and its effects on the physicochemical quality of drug product. Eur J Pharm Sci., 2017; 109(11): 347-358.

14. Jarvinen K, Hoehe W, Jariven M, Poutiainen S, Juuti $\mathrm{M}$, Borchert S, In-line monitoring of the drug content of powder mixturesand tablets by near-infrared spectroscopy during the continuous direct compression tableting process. Eur J Pharm Sci., 2013; 48(4-5): 680-688.

15. Markl D, Warman M, Dumarey M, Bergman E, Zeitler JA, Review of real-time release testing of pharmaceutical tablets: State-of-the art, challenges and future perspective. Int J Pharm., 2020; 582(5): 119353: 1-21.

16. Müllers KC, Wahl MA, Pinto JF, Multilayer laminar co-extrudate as a novel controlled release dosage form. Eur J Pharm Sci., 2013; 49(4): 491-498.

17. Müllers KC, Wahl MA, Pinto JF, Production of dosage forms for oral drug delivery by laminar extrusion of wet masses. Eur J Pharm Biopharm., 2013; 84(3): 626-632.

18. Oliveira G, Wahl MA, Pinto JF, Characterization of laminar extrudates manufactured at room temperature in the absence of solvents for the delivery of drugs. Int J Pharm., 2013; 454(1): 90-98.
19. Paisana MC, Wahl MA, Pinto JF, Role of moisture on the physical stability of polymorphic olanzapine. Int J Pharm., 2016; 509(1-2): 135-148.

20. Pauli V, Elbaz F, Kleinebudde P, Krumme M, Methodology for a variable rate control strategy developmentin continuous manufacturing applied to twin-screw wet-granulation and continuous fluidbed drying. J Pharm Innov., 2018; 13(4): 247-260.

21. Pauli V, Roggo Y, Pellegatti, Trung N, Elbaz F, Ensslin S, Kleinebudde P, Krumme M, Process analytical technology for continuous manufacturing tableting processing: a case study. J Pharm Biomed Anal., 2019; 162(1): 101-111.

22. Roggo Y, Pauli V, Jelsch M, Pellegatti, Elbaz F, Ensslin S, Kleinebudde P, Krumme M, Continuous manufacturing process monitoring of pharmaceutical solid dosage form: A case study. J Pharm Biomed Sci., 2020; 179(2): 1-12.

23. Roque-Flores RL, Jivaldo do Rosário Matos J, Simultaneous measurements of X-ray diffractiondifferential scanning calorimetry. The investigation of the phase transition of ganciclovir and characterization of its polymorphic forms. J Therm Anal Calorim., 2019; 137(4): 1347-1358.

24. Saerens L, Dierickx L, Lenain B, Vervaet C, Remon JP, De Beer T, Raman spectroscopy for the in-line polymer-drug quantification and solid state characterization during a pharmaceutical hot-melt extrusion process. Eur J Pharm Biopharm., 2011; 77(1): 158-163.

25. Sood J, Sapra B, Bhandari S, Jindal M, Tiwary AK, Understanding pharmaceutical polymorphic transformations I: influence of process variables and storage conditions. Ther Deliv., 2014; 5(10): 1123-1142.

26. Warnecke S, Rinnan A, Allesø M, Engelsen SB, Fluorescence spectroscopy in process analytical technology (PAT): simultaneous quantification of two active pharmaceutical ingredients in a tablet formulation. Appl Spectrosc., 2015; 69(3): 323-331.

27. Woertz Ch, Kleinebudde P, Development of orodispersible polymer films with focus on the solid state characterization of crystalline loperamide. Eur J Pharm Biopharm., 2015; 94(8): 52-63.

28. Zong Z, Desai SD, Kaushal AM, Barich DH, Huang H, Munson EJ, Suryanarayanan R, Kirsch LE, The stabilizing effect of moisture on the solid-state degradation. AAPS Pharm Sci Tech., 2011; 12(3): 924-931. 